Biochemical Engineering Journal 123 (2017) 38-44

Sara Mateo ${ }^{1}$, Adriana D`Angelo ${ }^{2}$, Onofrio Scialdone ${ }^{2}$, Pablo Cañizares ${ }^{1}$, Manuel Andrés Rodrigo ${ }^{1}$, Francisco Jesus Fernandez-Morales ${ }^{1 *}$

${ }^{1}$ University of Castilla-La Mancha, ITQUIMA, Chemical Engineering Department, Avenida Camilo José Cela S/N. 13071 Ciudad Real, Spain.

${ }^{2}$ Universita degli Studi di Palermo, Dipartimento di Ingegneria Chimica, Gestionale, Informatica, Meccanica, Viale delle Scienze, Palermo, Italy

\title{
The influence of sludge retention time on mixed culture microbial fuel cell start-ups
}

\begin{abstract}
In this work, the start-ups of air-cathode microbial fuel cells (MFCs) seeds with conventional activated sludge cultivated at different solid retention times (SRTs) are compared. A clear influence of the SRT of the inoculum was observed, corresponding to an SRT of 10 days to the higher current density exerted, about $0.2 \mathrm{~A} \mathrm{~m}^{-2}$. This observation points out that, in this type of electrochemical device, it is recommended to use high SRT seeds. The work also points out that in order to promote an efficient start-up, it is not only necessary to use high SRT seeds, but also to feed a high COD concentration. When feeding 10000 ppm COD and keeping SRT of $10 \mathrm{~d}$ differences of current densities up to $0.1 \mathrm{~A} \mathrm{~m}^{-2}$ were observed within a cycle. Additionally it was observed that SRT influences direct and indirect electron transfer mechanisms, being the direct mechanisms the most relevant ones, accounting for more than $95 \%$ of the total electricity production.
\end{abstract}

\section{Keywords}

Solid retention time; Microbial fuel cell; Air-cathode; Acetate 


\section{Introduction}

In recent years, research programs that focus on alternative technologies for the treatment of wastewater have attracted great interest $[1,2]$. One of the main objectives of these technologies is to develop self-sustainable wastewater treatment plants (WWTPs), able to reduce the significant energy consumption of conventional aerobic processes. In general, approximately one-third of the total operating cost of a WWTP is due to the energy requirements, and the energy consumed for the aeration represents approximately $60-65 \%$ of the total energy consumption [3]. Some of the most potentially promising technologies able to achieve self-sustainable WWTPs are the bio-electrochemical ones, which may attain in a single step the depletion of pollution and the conversion of the chemical energy contained in the pollutants into electrical energy. Amongst bio-electrochemical technologies, one of the most widely-studied in recent years is the Microbial Fuel Cell (MFC) [4-6], which is a complex device where the respiration of microorganisms is carried out, coupled to various electrochemical processes. In the MFC, the combination of biotechnology and electrochemistry leads to a very interesting field: bio-electrochemistry. Due to the complexity of bio-electrochemistry, there are many operating variables influencing the performances of an MFC [7].

In the existing literature it has been stated that the optimal performance of MFCs is obtained when the $\mathrm{pH}$ is within the range of 6.5-8.5, because this range stimulates the growth of electrogenic microorganisms [8]. MFC operation is also strongly affected by temperature, either due to kinetics and mass transfer (activation energy and mass transfer coefficient) [9], thermodynamics (free energy and electrodes potential), the external resistance [10], the feed rate [11, 12] hydrodynamics [13], anode geometry [14] or the nature and the distribution of microbial communities $[15,16]$. The contribution of all these parameters makes the MFC a very worthy topic for investigation $[17,18]$.

Regarding the start-up phase, it has been reported to be influenced by the external resistance [19-21] and the poised potential [22], because both parameters are related to the metabolic pattern of electrogenic microorganisms [23, 24]. In addition, when dealing with the start-up of an MFC, it is also important to evaluate the influence of the culture type (pure or mixed). When comparing pure and mixed cultures, it can be stated that mixed culture MFCs generally need a longer time to obtain a stable power output [22]. However, the use of mixed culture is preferred since it reduces the operational costs and presents a better adaptive capacity, owing to microbial diversity $[16,25,26]$.

Concerning the mixed microbial communities, a well-known selective parameter for almost all the bioprocesses is the sludge age, also known as sludge retention time (SRT) [27] . This is because this parameter controls the microorganisms growing in the system. Microorganisms unable to grow in the defined retention time are washed-out, allowing only the growth of fast growing microorganisms in the liquid bulk [25]. In the case of the start-up of an MFC, only the microorganisms growing in the liquid bulk are able to attach to the electrode. Thus, the population in the electrode of a mixed culture MFC clearly depends on the SRT of the inoculum and on the SRT fixed during the operation.

In spite of the high influence of the SRT, only studies related to the SRT on the operation have been published and, to the knowledge of the authors, no studies have been focused on 
the SRT influence over the start-up of an MFC. Because of that, the objective of this research was to evaluate the effect of the SRT on the start-up stage of an MFC.

\section{Materials and Methods}

Five different fed-batch air-breathing MFCs were simultaneously seeded under different SRTs, chosen in a large range in order to identify the best operative conditions for the start-up stage. In order to ensure the reproducibility, three runs were performed.

The MFC used in this work was made of methacrylate material, consisted of two chambers of $0.346 \mathrm{~cm}^{3}$, separated by a commercial high ion exchange capacity $\left(0.9-0.02 \mathrm{meq} \mathrm{g}^{-1}\right)$, high ionic conductivity $\left(8 \cdot 10^{-2} \mathrm{~S} \mathrm{~cm}^{-1}\right)$ and a low electronic conductivity $\left(<10^{-10} \mathrm{~S} \mathrm{~cm}^{-1}\right)$ Sterion ${ }^{\circledR}$ proton exchange membrane (Alfa Aesar, Heysham, UK). Toray carbon papers (Fuel Cell Store, Texas, USA) were used as electrodes with an active area of $0.86 \mathrm{~cm}^{2}$ in both chambers: $10 \%$ of the anode's and $20 \%$ of the cathode's structure was Teflon because of its mechanical properties [28]. Additionally, an homogenous catalytic layer of $0.5 \mathrm{mg} \mathrm{Pt}$ $\mathrm{cm}^{-2}$ was deposited on to the microporous layer of the cathode according to the literature [9]. This catalytic layer increases the reduction rate of the oxygen from the air entering upon the cathodic chamber [28]. Anodic and cathodic electrodes were connected by an external circuit with a resistance of $120 \Omega$. This load is commonly used when operating with air-cathode MFC [9, 29]. The electrodes and the proton exchange membrane underwent a process of assembly to reduce the internal resistance. To do that, the electrodes were introduced between two stainless steel blocks equipped with heating surfaces brought under progressive and controlled heating until a temperature of $120^{\circ} \mathrm{C}$ was reached and, at this temperature, a load of one ton was applied for four minutes. More information about the assembly process can be found in the literature [9]. Every MFC was connected to an auxiliary reservoir of about $125 \mathrm{~mL}$. Initially the reservoir was used to seed the MFC. Once seeded the MFC, the reservoir was used to store the wastewater used for feeding the MFC. Moreover, the daily purge was carried out from the reservoirs. A scheme of the MFC configuration can be seen in Figure 1.

\section{[FIGURE 1 NEAR HERE]}

At the beginning of the test, $114 \mathrm{~mL}$ of synthetic medium was added to the auxiliary reservoir of anodic compartment. The reservoirs were purged with nitrogen gas in order to ensure anaerobic conditions thorough the MFC operation. The concentration in the medium was $5.8 \mathrm{~g} \mathrm{~L}^{-1}$ of sodium acetate as the sole carbon source (4000 ppm of COD), supplemented with the following trace minerals: $0.26 \mathrm{~g} \mathrm{~L}^{-1}$ of sodium carbonate, $0.18 \mathrm{~g} \mathrm{~L}^{-1}$ of ammonium sulfate, $0.11 \mathrm{~g} \mathrm{~L}^{-1}$ of potassium dihydrogen phosphate, $0.09 \mathrm{~g} \mathrm{~L}^{-1}$ of magnesium chloride, $0.07 \mathrm{~g} \mathrm{~L}^{-1}$ of calcium chloride and $0.02 \mathrm{~g} \mathrm{~L}^{-1}$ of ferric ammonium sulfate. Then, each MFC was seeded by adding $1 \mathrm{~mL}$ of activated sludge to the auxiliary reservoir. As inoculum, it was used activated sludge from a conventional aerobic WWTP, described elsewhere [30]. Before the inoculation, the activated sludge was aerated overnight in order to reduce its organic pollutants content [31]. In order to obtain MFCs working with different SRTs, the anodic reservoir of each MFC was daily purged and the discarded volume replaced. The purge implemented in each MFC led to SRT of 10, 7.4, 5, 2.5 and 1.4 days, according to Eq. 1: 
$\frac{V_{\text {reactor }}(m L)}{V_{\text {purged }}(m L / d)}=S R T(d)$

In order to evaluate the influence of the organic load and the inoculum, in subsequent stages the medium organic load was 2.5 times the initial one, therefore containing $14.5 \mathrm{~g} \mathrm{~L}^{-}$

${ }^{1}$ of sodium acetate (10000 ppm of COD), so the corresponding trace minerals and the volume of the inoculum was proportionally increased.

The synthetic wastewater was fed by a Peristaltic Pump (Heidolph PD-5206 Peristaltic Dosing Dispensing Pump Drive) at $3 \mathrm{~mL} \mathrm{~min}{ }^{-1}$. A GLP22 Crison $\mathrm{pH}$-meter was used to measure the $\mathrm{pH}$. The COD concentration was measured according to standard methods [32]. The evolution of the potential was continuously recorded in a computer connected to a digital multimeter (Keithley® 2000). Metabolism intermediates were monitored by HPLC (Agilent Technologies, Germany), equipped with a UV-DAD detector. The detector cell and the column operated under a temperature of $25^{\circ} \mathrm{C}$ and the reference wavelength was 360/80 nm. A Zorbax SB-Aq 4,6 x $150 \mathrm{~mm} \mathrm{5-microm} \mathrm{(Agilent)} \mathrm{column} \mathrm{was} \mathrm{used}$ [25]. The mobile phase was a $20 \mathrm{Mm}$ aqueous solution of $\mathrm{NaH}_{2} \mathrm{PO}_{4}$ and $\mathrm{H}_{3} \mathrm{PO}_{4}$.

\section{Results and Discussion}

To study the effect of different parameters over the start-up of a microbial fuel cell, each set of MFC operating at the different SRT were seeded simultaneously. The MFC were operated under the same operating conditions, feeding acetate as the sole carbon source. The MFCs were configured with brand new electrodes; therefore, the electrode surfaces at the beginning of the experiments were absolutely clean. Because of that, the results presented in this work are directly related to the effect of the SRT on the microbial selection and on the biofilm fixation on the surface of the electrode. Taking into account the vigorous stirring in the auxiliary reservoir connected to the anodic compartment of the MFC and the continuous pumping between the auxiliary tank and the MFC, the hydraulic retention time matched the SRT (ranging from 1.4 to 10.0 days) during the start-up stage.

\section{COD removal}

In Fig. 2a, the time changes in the influent and effluent COD in each of the five MFCs is presented. In this figure, it can be observed that the higher the SRT, the higher the COD removal during the three stages marked in the figure.

[FIGURE 2 NEAR HERE]

This observation is more evident when working at SRTs of 5.0, 7.4 and 10.0 days. Under these conditions, the effluent COD is negligible, pointing out the capacity of MFC to deplete the fed organic load. The influence of the SRT on the performance of the biooxidation of organics is well-known, and it is usually explained in terms of the higher activated sludge concentration in the mixed liquor, associated with the lower purge ratio applied at higher SRTs [33].

\section{Electricity production}

As pointed out before, the organic load and the inoculum volume were modified during the experiments. These changes defined the three different stages presented in Figure 2. These changes were made in order to search for a more efficient and faster electricity production. In the first stage, the start-up of the MFCs was carried out with a concentration of COD of 
$4000 \mathrm{ppm}$ and with a very small amount of inoculums (1\% v/v). The results point out that although microorganisms degrade the substrate efficiently, the concentration of electrogenic ones is likely to be very low. Indeed, no relevant production of electricity was obtained (values under $0.02 \mathrm{~A} \mathrm{~m}^{-2}$ for all the SRTs adopted). Initially, these results might be explained in terms of the low concentration of inoculum seeded $(1 \% \mathrm{v} / \mathrm{v})$ and its source, the aerobic reactor of a conventional WWTP, in which a very low content of electrogenic microorganisms was expected. In any event, the production of electricity from the very beginning suggests that these types of electrogenic microorganisms are contained in raw activated sludge, although their role in the biological processes of conventional WWTPs is obviously negligible.

In order to increase the electrogenic population in the MFC, and hence to try to speed up the start-up process, a second inoculation was made to the five MFCs. In this second inoculation, carried out on the $10^{\text {th }}$ day, the re-inoculation was carried out maintaining the set-up without any modification. In this re-inoculation, the percentage of inoculum was increased from $1 \% \mathrm{v} / \mathrm{v}$ to $10 \% \mathrm{v} / \mathrm{v}$. After the second inoculation, the COD removal was enhanced, reaching very low effluent values at all the SRTs tested. However, once again no significant increase in the electricity generation was observed after one week of operation, which indicates that this strategy again fails to efficiently produce electricity. At this point, it is important to remark that only the MFC seed with an SRT of 10.0 days showed a slight increase in the current generation. Obviously, the population of microorganisms contained in the MFC was in large part non-electrogenic, but the amount of microorganisms contained was sufficient to deplete the organic substrates contained in the fed fuel solution. Because of the lack of organic substrate, it was difficult for the electrogenic microorganisms to compete efficiently, in particular taking into account the origin of the seeded sludge. This observation has been previously reported in the literature [34-39]. Because of that, it was decided to increase the concentration of COD from 4000 to $10000 \mathrm{ppm}$, in order to give electrogenic microorganisms more opportunities to grow in this system. The results are shown in the so-called Stage 3 of Figure 2.

The later change had the expected positive effect on the production of electricity in all the five MFCs. It is worth mentioning that in the stage II, both the COD consumption rate and the production of electricity increased with SRT. Thus, the output current values were $0.032,0.061,0.065,0.069$ and $0.153 \mathrm{~A} \mathrm{~m}^{-2}$ for the SRTs of 1.4, 2.5, 5.0, 7.4 and 10.0 days, respectively. The COD consumption rate, which takes into account that MFC operates in semi-continuous mode, was 1.01, 1.36, 1.01, 1.77 and $1.72 \mathrm{~g} \mathrm{COD} \mathrm{L}^{-1} \mathrm{~d}^{-1}$. As can be seen from these results, COD removal was not directly coupled with electric current generation by the MFC. This different behavior has to be explained in terms of the competition of electrogenic and non-electrogenic microorganisms for the acetate. From the exerted current, an estimation of the percentage of COD consumed to produce electricity could be obtained. The relationship between exerted current and COD consumption by microorganisms can be defined as the coulombic efficiency (CE) [40]. This parameter can be evaluated by taking into account the relationship between the COD removal rate and the theoretical current intensity. Therefore, the $\mathrm{CE}$ is defined as the ratio of total quantity of Coulombs actually transferred from the substrate to the anode, to the maximum possible Coulombs transferred if all the substrate removal generated current. The CE can be determined by integrating over time the Coulombs actually transferred divided by the stoichiometric theoretical value (eq. 7). 
$\mathrm{CE}=\frac{\mathrm{M} \cdot \int_{0}^{\mathrm{t}} \mathrm{I} \cdot \mathrm{dt}}{\mathrm{n} \cdot \mathrm{F} \cdot \mathrm{V}_{\text {anodic }} \cdot \mathrm{r}_{\mathrm{COD}}}$

Where $\mathrm{M}$ is the oxygen molar mass, $\mathrm{I}$ is the intensity of the electrical current exerted by the MFC, $\mathrm{t}$ is the time, $\mathrm{n}$ is the actual electrons transferred in this case $4 \mathrm{mmol}$ of e- per mmol of COD, $\mathrm{F}$ is the Faraday constant $\left(96485 \mathrm{C} \mathrm{mol}^{-1} \mathrm{e}^{-}\right), \mathrm{V}_{\text {anodic }}$ is the anodic volume and $\mathrm{r}_{\mathrm{COD}}$ the COD removal rate.

In this way, the $\mathrm{CE}$ of the experiments can be determined, ranging its value in this work from 6.5 to $17.8 \%$, corresponding to the highest values with the highest SRT.

The increase in the electrogenic activity with the SRT can be explained by considering the higher microbial growth in the MFC seed at larger SRTs, which favors the proliferation of the slow-growing electrogenic microorganisms. In the particular case of two well-known electroactive microorganisms: Shewanella and Geobacter, it has been reported [37, 39, 41] that a maximum growth rate of $2.4 \mathrm{~d}^{-1}$ can occur, whereas other anaerobic non electrogenic microorganisms present higher maximum specific growth rate values [34, 42]. The different growth rates would lead to mixed cultures, enriched in electrogenic microorganisms when operating at the high SRT. To ratify this theory, the microbial culture obtained in each experiment was analyzed by means of Illumina MiSeq. From the analysis, it was observed that the higher relative abundance of the electroactive microorganisms, Shewanella and Geobacter, in both the reservoir tank and the electrode biofilm were obtained when operating at 10 days of SRT.

In general, the values obtained for the $\mathrm{CE}$ in this work are very low, especially when they are compared to values obtained in other works previously published in the relevant literature $[9,40]$. This indicates that although the promotion of electrogenic microorganisms is attained, some processes are limiting the optimum performance of the electrogenic culture. Thus, in the MFCs used in this work, both consortiums coexist and the applied operation conditions, as well as the nature of the substrate, determine the prevalence of one of them with respect to the other.

It seems interesting to observe that the lag time between the change in the conditions and the production of electricity (see Fig. 2b, Stage III) seems to decrease when the SRT is increased. This result can be explained by considering the higher population of microorganisms in the MFC seed at larger SRTs, which could favor the proliferation of electrogenic microorganisms.

\section{$\underline{\text { Daily cycles }}$}

As explained before, the MFCs were daily fed by replacing, with fresh medium, the defined volume to attain the required SRT. This procedure generated daily profiles in both COD and current, which stabilize over long periods due to the very different time constants of the processes involved (from a process-dynamic point of view). Thus, changes within long periods, such as those applied in the tests carried out in this work, have to be evaluated, considering that the MFC behaves as a completely mixed tank reactor. In turn, in order to evaluate performances over short periods of time (a time scale of hours), such 
as the daily changes of the COD, it is better to consider the MFC as a discontinuous system. Because of that, Eq. 4 can be used to determine the COD removal:

$r V=-V \frac{d C O D}{d t}$

where $r$ is the mineralization rate, $V$ the solution volume and $t$ the time.

To illustrate these behaviors, the cycles obtained in the MFC seed at an SRT of 5.0 days are shown in Figure 3. The performances over the first (almost no electricity production) and third (electricity produced efficiently) stages of the start-up process are illustrated. In these figures the current density and the COD profiles are presented.

\section{[FIGURE 3 NEAR HERE]}

Within the so-called Stage I, the cycles were almost negligible, as expected, taking into account the low production of electricity. As described before, Stage I corresponds to a system with a low biomass concentration and with an influent COD of $4000 \mathrm{ppm}$, for which the electrogenic culture was not fully developed. Hence, the COD was consumed almost exclusively by non-electrogenic microorganisms. In any event, even at these negative conditions for electrogenic bacteria, an appreciable difference of about $0.01 \mathrm{~A} \mathrm{~m}^{-2}$ between the maximum and the minimum in the electric current profile was observed. Conversely, the conditions of Stage III are better for the production of electricity, because of the higher concentration of microorganisms, caused by a more concentrated inoculum and the higher influent COD, and this is reflected in the greater differences observed in the current profiles, which increase up to $0.04 \mathrm{~A} \mathrm{~m}^{-2}$ during the day.

The profiles observed in Figure 3 for the MFC seed at 5.0 days of SRT were also reproduced in the other four MFCs' seeds at 1.4, 2.5, 7.4 and 10.0 days, as shown in Fig. 4. [FIGURE 4 NEAR HERE]

In addition to the reproducibility in the daily profiles, it is interesting to observe that the higher the SRT, the more shaped are the cycles, with maximum differences in the instantaneous current density that range between $0.01 \mathrm{~A} \mathrm{~m}^{-2}$ (SRT: $1.4 \mathrm{~d}$ ) and $0.14 \mathrm{~A} \mathrm{~m}^{-2}$ (SRT: $10.0 \mathrm{~d}$ ) in one day. This increase is related to the higher production of electricity in MFC with increasing SRT, due to the microbial selection previously described.

\section{Direct and indirect electron transfer}

In order to evaluate the role of electron transfer mechanisms at different SRTs, the direct and indirect electron transfer mechanisms were evaluated separately. To do that, sequence batch reactors working under the same range of SRT were operated. Once it had reached the steady state, the mixed liquor was filtered through a glass fiber filter $(45 \mu \mathrm{m})$ and fed to a brand-new air-cathode MFC. The MFC was operated for several days, without seeding any microorganisms. In this case, the solution passed the MFC just once (no re-circulation) in order to prevent the formation of biofilm over the electrode, with the aim to elucidate the effect of potential mediators produced in the biological reactors. The goal was to determine how redox species can directly interact with the electrode and generate an electrical current. Fig. 5 presents a comparison between the steady-state current density generated by the air-breathing MFC and the values obtained when feeding the filtered solution containing the mediators. Both trends are similar, with a higher production of electricity following the increase in the SRT, although the use of a logarithmic scale was necessary because of the huge difference in the electric current produced. 
The large difference in current density observed in the conventional MFCs and when the bioreactor's effluent was fed, clearly indicates a low contribution of mediators in the generation of electricity. This observation suggests that the main process associated with the production of electricity in the microbial fuel cells is the direct transfer of electrons to the anode. This could explain the low performance of the microbial fuel cell set-up used in this work, characterized by a large volume in the auxiliary tank. In this case, the ratio electrode surface to bulk volume was low, which is very unfavorable for the promotion of fixed culture processes. Another important point in the comparison of both experiments is the different effluent COD concentration after the treatment. Although trends are similar, the values are not as similar as expected, clearly pointing out that the electrogenic microorganisms growing in the MFC play a significant role in the COD consumption.

\section{pH evolution and metabolic intermediates}

A last important point is the change in $\mathrm{pH}$. The $\mathrm{pH}$ is an easy-to-follow parameter that summarizes the effect on the mixed liquor of different processes. The changes in this parameter during the experiments are shown in Figure 6 for the five MFCs tested and they bring up a final important piece of information that can be taken from this study.

[FIGURE 6 NEAR HERE]

Conversely, it could be expected that there might be a monotonous trend up or down to stabilization, with $\mathrm{pH}$ changed in a non-predicted but, at the same time, reproducible way (the same trend in the five cells). The $\mathrm{pH}$ showed a descending trend during the first stage in the five cells, which was more important in the MFCs' seed at low SRT. Then, this situation reverses in the third stage, where the $\mathrm{pH}$ increases with time in all the five cells. These changes in the $\mathrm{pH}$ suggest that the change in the concentration of COD fed to MFCs made in Stage III also produces a change in the metabolism of microorganisms, which can help to explain the improvement in the electrogenic culture. In order to evaluate the change in the microbial metabolisms, the main metabolic intermediates were analyzed. From these analyses, it was observed that the higher the SRT, the higher the lactate concentration. This is important because in the literature it has been observed that lactate can be used by electrogenic microorganisms to produce electricity [43]. 


\section{Conclusions}

From this work the following conclusions can be drawn on the start-up of MFCs:

- Electric current produced depends on the SRT at which MFC are seeded. The higher the SRT, the higher is the electricity produced.

- To speed up the start-up processes, a suitable inoculation of the system and a high COD are required.

- Daily cycles in the production of electricity also reflect the positive effect of SRT.

- Although electricity production by mediated processes is also related to SRT, its contribution is very low and almost negligible, as compared to that of direct processes.

\section{Acknowledgements}

Financial support from the AEI (Agencia Estatal de Investigación) of the Spanish Ministry of Economy and Competitiveness (MINECO) through project CTQ2013-49748-EXP (Explora Program) is gratefully acknowledged 


\section{References}

[1] L. Moreno, M. Nemati, B. Predicala, Biokinetic evaluation of fatty acids degradation in microbial fuel cell type bioreactors, Bioprocess and Biosystems Engineering, 38 (2015) 25-38.

[2] A.E. Franks, K.P. Nevin, Microbial fuel cells, a current review, Energies, 3 (2010) 899-919.

[3] F.J. Fernández, M.C. Castro, M.A. Rodrigo, P. Cañizares, Reduction of aeration costs by tuning a multi-set point on/off controller: A case study, Control Engineering Practice, 19 (2011) 1231-1237.

[4] G. Chen, F. Zhang, B.E. Logan, M.A. Hickner, Poly(vinyl alcohol) separators improve the coulombic efficiency of activated carbon cathodes in microbial fuel cells, Electrochemistry Communications, 34 (2013) 150-152.

[5] M. Rimboud, E. Desmond-Le Quemener, B. Erable, T. Bouchez, A. Bergel, The current provided by oxygen-reducing microbial cathodes is related to the composition of their bacterial community, Bioelectrochemistry, 102 (2015) 42-49.

[6] S. Mateo, A. Gonzalez del Campo, P. Cañizares, J. Lobato, M.A. Rodrigo, F.J. Fernandez, Bioelectricity generation in a self-sustainable Microbial Solar Cell, Bioresource Technology, 159 (2014) 451-454.

[7] V.M. Ortiz-Martínez, M.J. Salar-García, A.P. de los Ríos, F.J. Hernández-Fernández, J.A. Egea, L.J. Lozano, Developments in microbial fuel cell modeling, Chemical Engineering Journal, 271 (2015) 50-60.

[8] A.J.C. da Silva, E.V. dos Santos, C.C. de Oliveira Morais, C.A. Martínez-Huitle, S.S.L. Castro, Electrochemical treatment of fresh, brine and saline produced water generated by petrochemical industry using Ti/IrO2-Ta2O5 and BDD in flow reactor, Chemical Engineering Journal, 233 (2013) 47-55.

[9] A. Gonzalez del Campo, J. Lobato, P. Cañizares, M.A. Rodrigo, F.J. Fernandez Morales, Shortterm effects of temperature and COD in a microbial fuel cell, Applied Energy, 101 (2013) 213-217. [10] M. Di Lorenzo, T.P. Curtis, I.M. Head, K. Scott, A single-chamber microbial fuel cell as a biosensor for wastewaters, Water Research, 43 (2009) 3145-3154.

[11] I. Ieropoulos, J. Greenman, C. Melhuish, Improved energy output levels from small-scale Microbial Fuel Cells, Bioelectrochemistry, 78 (2010) 44-50.

[12] M. Di Lorenzo, K. Scott, T.P. Curtis, I.M. Head, Effect of increasing anode surface area on the performance of a single chamber microbial fuel cell, Chemical Engineering Journal, 156 (2010) 4048.

[13] L. Zhao, J. Li, F. Battaglia, Z. He, Investigation of multiphysics in tubular microbial fuel cells by coupled computational fluid dynamics with multi-order Butler-Volmer reactions, Chemical Engineering Journal, 296 (2016) 377-385.

[14] T. Tommasi, A. Sacco, C. Armato, D. Hidalgo, L. Millone, A. Sanginario, E. Tresso, T. Schilirò, C.F. Pirri, Dynamical analysis of microbial fuel cells based on planar and 3D-packed anodes, Chemical Engineering Journal, 288 (2016) 38-49.

[15] E. Martin, O. Savadogo, S.R. Guiot, B. Tartakovsky, The influence of operational conditions on the performance of a microbial fuel cell seeded with mesophilic anaerobic sludge, Biochemical Engineering Journal, 51 (2010) 132-139.

[16] M. de los Ángeles Fernandez, M. de los Ángeles Sanromán, S. Marks, J. Makinia, A. Gonzalez del Campo, M. Rodrigo, F.J. Fernandez, A grey box model of glucose fermentation and syntrophic oxidation in microbial fuel cells, Bioresource Technology, 200 (2016) 396-404.

[17] J.E. Mink, R.M. Qaisi, B.E. Logan, M.M. Hussain, Energy harvesting from organic liquids in micro-sized microbial fuel cells, Npg Asia Materials, 6 (2014).

[18] J. Heilmann, B.E. Logan, Production of electricity from proteins using a microbial fuel cell, Water Environment Research, 78 (2006) 531-537. 
[19] P. Aelterman, M. Versichele, M. Marzorati, N. Boon, W. Verstraete, Loading rate and external resistance control the electricity generation of microbial fuel cells with different threedimensional anodes, Bioresource Technology, 99 (2008) 8895-8902.

[20] S. Jung, J.M. Regan, Influence of external resistance on electrogenesis, methanogenesis, and anode prokaryotic communities in microbial fuel cells, Applied and Environmental Microbiology, 77 (2011) 564-571.

[21] K.P. Katuri, K. Scott, I.M. Head, C. Picioreanu, T.P. Curtis, Microbial fuel cells meet with external resistance, Bioresource Technology, 102 (2011) 2758-2766.

[22] X. Wang, Y. Feng, N. Ren, H. Wang, H. Lee, N. Li, Q. Zhao, Accelerated start-up of twochambered microbial fuel cells: Effect of anodic positive poised potential, Electrochimica Acta, 54 (2009) 1109-1114.

[23] U. Schröder, Anodic electron transfer mechanisms in microbial fuel cells and their energy efficiency, Physical Chemistry Chemical Physics, 9 (2007) 2619-2629.

[24] K. Rabaey, J. Rodríguez, L.L. Blackall, J. Keller, P. Gross, D. Batstone, W. Verstraete, K.H. Nealson, Microbial ecology meets electrochemistry: Electricity-driven and driving communities, ISME Journal, 1 (2007) 9-18.

[25] F.J. Fernández, J. Villaseñor, D. Infantes, Kinetic and stoichiometric modelling of acidogenic fermentation of glucose and fructose, Biomass and Bioenergy, 35 (2011) 3877-3883.

[26] K. Rabaey, G. Lissens, S.D. Siciliano, W. Verstraete, A microbial fuel cell capable of converting glucose to electricity at high rate and efficiency, Biotechnology Letters, 25 (2003) 1531-1535.

[27] G. Tchobanoglous, F.L. Burton, Metcalf, Eddy, Wastewater engineering : treatment, disposal, and reuse, McGraw-Hill, New York, 1991.

[28] S. Mateo, M. Rodrigo, L.P. Fonseca, P. Cañizares, F.J. Fernandez-Morales, Oxygen availability effect on the performance of air-breathing cathode microbial fuel cell, Biotechnology Progress, 31 (2015) 900-907.

[29] S. Mateo, A. Gonzalez del Campo, J. Lobato, M. Rodrigo, P. Cañizares, F.J. Fernandez-Morales, Long-term effects of the transient COD concentration on the performance of microbial fuel cells, Biotechnology Progress, 32 (2016) 883-890.

[30] L. Rodríguez Mayor, J. Villaseñor Camacho, F.J. Fernández Morales, Operational optimisation of pilot scale biological nutrient removal at the Ciudad Real (Spain) domestic wastewater treatment plant, Water, Air, and Soil Pollution, 152 (2004) 279-296.

[31] A. De Lucas, L. Rodríguez, J. Villaseñor, F.J. Fernández, Biodegradation kinetics of stored wastewater substrates by a mixed microbial culture, Biochemical Engineering Journal, 26 (2005) 191-197.

[32] E.A.D.A.W.W.A.W.E.F. American Public Health Association, Standard methods for the examination of water and wastewater, APHA-AWWA-WEF, Washington, D.C., 2005.

[33] J. Makinia, S.A. Wells, A general model of the activated sludge reactor with dispersive flow - I. Model development and parameter estimation, Water Research, 34 (2000) 3987-3996.

[34] F.J. Fernández-Morales, J. Villaseñor, D. Infantes, Modeling and monitoring of the acclimatization of conventional activated sludge to a biohydrogen producing culture by biokinetic control, International Journal of Hydrogen Energy, 35 (2010) 10927-10933.

[35] H.S. Lee, P. Parameswaran, A. Kato-Marcus, C.I. Torres, B.E. Rittmann, Evaluation of energyconversion efficiencies in microbial fuel cells (MFCs) utilizing fermentable and non-fermentable substrates, Water Research, 42 (2008) 1501-1510.

[36] M. Sjöblom, L. Matsakas, P. Christakopoulos, U. Rova, Production of butyric acid by Clostridium tyrobutyricum (ATCC25755) using sweet sorghum stalks and beet molasses, Industrial Crops and Products, 74 (2015) 535-544. 
[37] D.E. Holmes, L. Giloteaux, M. Barlett, M.A. Chavan, J.A. Smith, K.H. Williams, M. Wilkins, P. Long, D.R. Lovley, Molecular analysis of the In situ growth rates of subsurface geobacter species, Applied and Environmental Microbiology, 79 (2013) 1646-1653.

[38] C. Risso, J. Sun, K. Zhuang, R. Mahadevan, R. DeBoy, W. Ismail, S. Shrivastava, H. Huot, S. Kothari, S. Daugherty, O. Bui, C.H. Schilling, D.R. Lovley, B.A. Methé, Genome-scale comparison and constraint-based metabolic reconstruction of the facultative anaerobic Fe(III)-reducer Rhodoferax ferrireducens, BMC Genomics, 10 (2009) 447.

[39] Y. Zhang, C.K. Ng, Y. Cohen, B. Cao, Cell growth and protein expression of Shewanella oneidensis in biofilms and hydrogel-entrapped cultures, Molecular BioSystems, 10 (2014) 10351042.

[40] J. Lobato, P. Cañizares, F.J. Fernández, M.A. Rodrigo, An evaluation of aerobic and anaerobic sludges as start-up material for microbial fuel cell systems, New Biotechnology, 29 (2012) 415420.

[41] C. Picioreanu, I.M. Head, K.P. Katuri, M.C.M. van Loosdrecht, K. Scott, A computational model for biofilm-based microbial fuel cells, Water Research, 41 (2007) 2921-2940.

[42] D. Infantes, A. González del Campo, J. Villaseñor, F.J. Fernández, Kinetic model and study of the influence of $\mathrm{pH}$, temperature and undissociated acids on acidogenic fermentation, Biochemical Engineering Journal, 66 (2012) 66-72.

[43] S. Ishii, S. Suzuki, T.M. Norden-Krichmar, T. Phan, G. Wanger, K.H. Nealson, Y. Sekiguchi, Y.A. Gorby, O. Bretschger, Microbial population and functional dynamics associated with surface potential and carbon metabolism, ISME Journal, 8 (2014) 963-978. 